\title{
Brief Introduction to a Bionic Lizard Flywheel Planing
}

\section{Craft}

Liang Hou and Liang Yun

\author{
XI-YI High Speed Craft Bionic Science \& Technology Ltd XYL Shanghai China
}

\begin{abstract}
Based on the research, simulation and experimental investigation of Basilisk Lizard running on the water surface, and similar experimental investigation of the craft models and practical crafts running on the water surface for about 30 years. The Bionic Lizard Flying Wheel Planing Craft was created and invented. This paper describes the evolution, experimental investigation, test results, design features, advantages, applications, and prospect of the innovation, which denotes the craft with excellent speed performance (high speed, extra STOL (short take-off and landing distance) and VTOL(vertical take-off and landing) characteristics, good transverse and longitudinal stability, super shallow water draft, high propulsion efficiency at high speed without cavitations obstacle, low external field noise, small dimension, simple configuration and structure, good economy, nice transportation efficiency, and possibly is first of these kinds in the HPMV (High Performance Marine Vessels) family around the world.
\end{abstract}

Keywords: Bionic technology, basilisk lizard, planing craft, flying wheel, high performance marine vessel, propeller, cavitations, ram wing, surface effect craft, take-off and landing.

\section{Back Ground of Bionic Technology}

Most of animals, in nature, are depending on the motion speed to prey and escape. So the motion speed is very important for protecting the life of themselves, and also being one of important factors for the human beings. However, since the density of water is greater than air for 800 times, the speed of fishes, moving in the water, should be lower than birds in the air for many times due to the greater water resistance, and with lower speed. So the best way to speed up fishes is trying to move in the air but not in the water.

The Basilisk Lizard lives in the tropic rain forest of South America, who has a special capability, being able to run fast on the water surface, with speed of 1.5 $\mathrm{m} / \mathrm{s}$, but not according to the water buoyancy (like ordinary fish), or according to the laminar layer automatic control technology for reducing water resistance, or even instantly flying in the air, like dolphin and other flying fishes, but according to his huge palmate feet, running with high frequency on the

Corresponding author: Liang Yun, professor, research fields: High Performance Marine Vessel Design. Email: Bliangyun@126.com. water surface, not in terms of air cushion, surface extension force, but in terms of impacting vertically on the water surface, so as to produce a great lift to support his body weight and running beyond the water with small air resistance and obtaining high speed over the water surface. As shown in Fig. 1.

Although the movement mechanism is known, however, it is not easy to learn this bionic, one of top 10 bionic technologies around the world, to apply for human being. In this research field, Carnegie Mellon University of US developed its "water runner robot" weighing $24 \mathrm{~g}$, in his robot lab could well simulated the motion of the Basilisk Lizard with its leg motion mechanism and realized the basic function of the motion mechanism at speed of $0.8 \mathrm{~m} / \mathrm{s}$ as shown in Fig. 2.

\section{The Evolution of "Bionic Lizard-Flying Wheel Planing Craft” in China}

Mr. Liang Hou is a unique researcher working on the bionic technology, developing from this technology to simulate and develop the practical water transportation tool in China, and possibly around the 


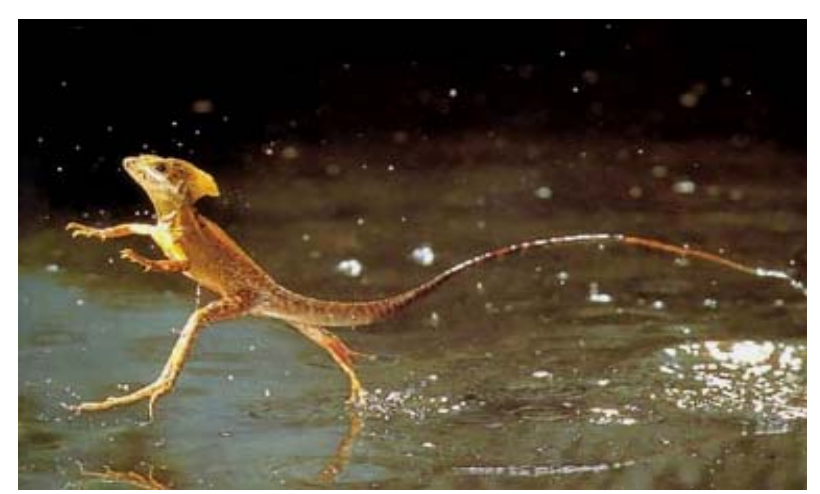

Fig. 1 The running gesture of a Lizard.

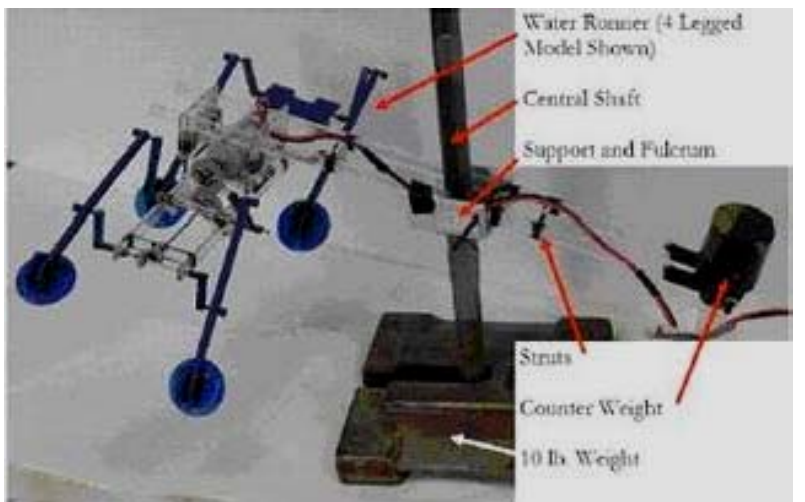

Fig. 2 "Water running robot" of Carnegie Mellon University, US.

world. He spent about 30 years to do the model and theoretical investigation on the bionic Lizard technology and then developed it as a Bionic Lizard Flying Wheel Planing Craft with super high speed, good stability, using flying wheel as a special propulsion equipment instead of ordinary propeller: water propeller, water jet propulsion, air propeller, ducted air propeller, and water-air jet propulsion, etc., but using a pair of flying wheels as the propulsion equipment with high revolution, just like the palmate feet of Lizard, and taking circular motion of wheels instead of linear motion of Lizard, producing a great lift, supporting the weight of craft and also thrust, so as to obtain both high propulsion efficiency and transportation efficiency as well as other nice speed performance of the high speed craft without any cavitations obstacle, so this is a novel and unique innovative propulsion equipment and craft around the world so far. Please do note: This is not old "paddle boat” developed in 19 century with lower propulsion efficiency, running on Mississippi river with low ship speed, but with rather different working mechanism and function, which will be described as follows.

A lot of model tests have been carried out by the researchers of Mr. Hou's research team in past three decades, including some self-propulsion radio remote control models as shown in Fig. 3.

Upon the successful model tests of the BLFW, seven test crafts have been manufactured and tested in past years, and got satisfied operational performance, and the profile and its dimension of the 6th test craft is shown in Figs. 4-6;

At present, Mr. Hou and his research team are working on the design and construction of some real crafts with bigger size for some applications.

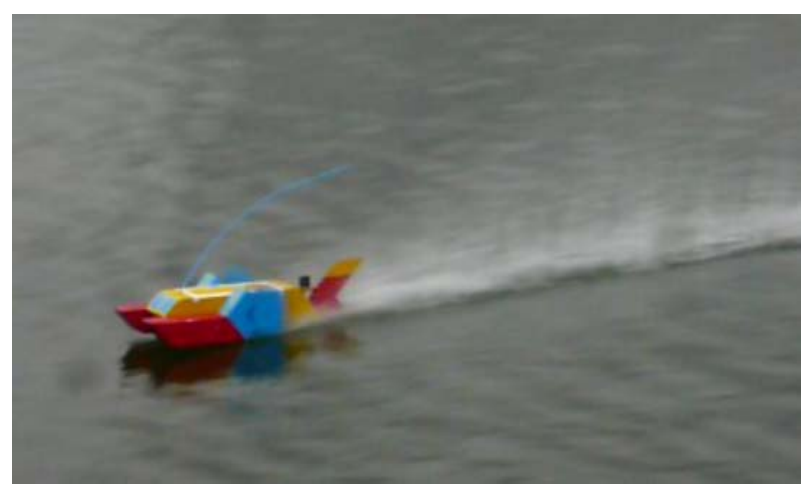

Fig. 3 Self-propulsion model.

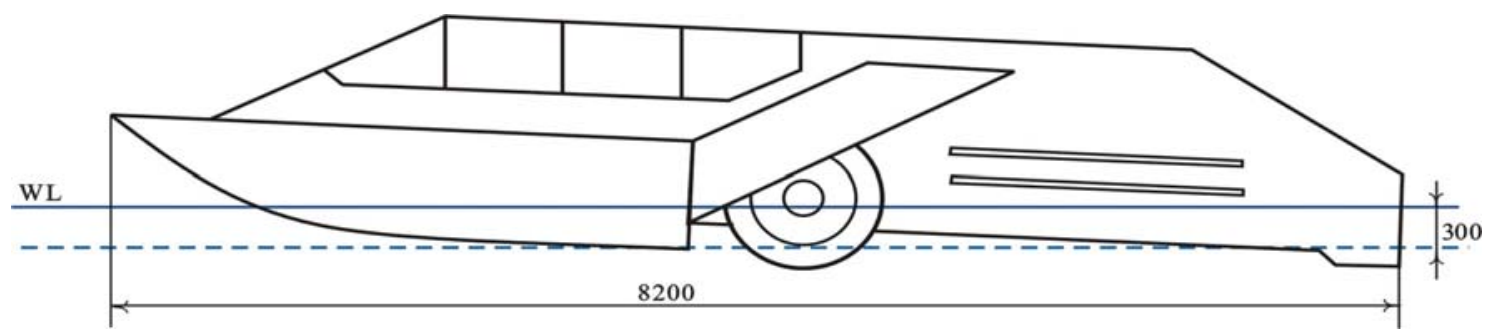

Fig. 4 Profile dimension of the 6th test BLFW craft. 


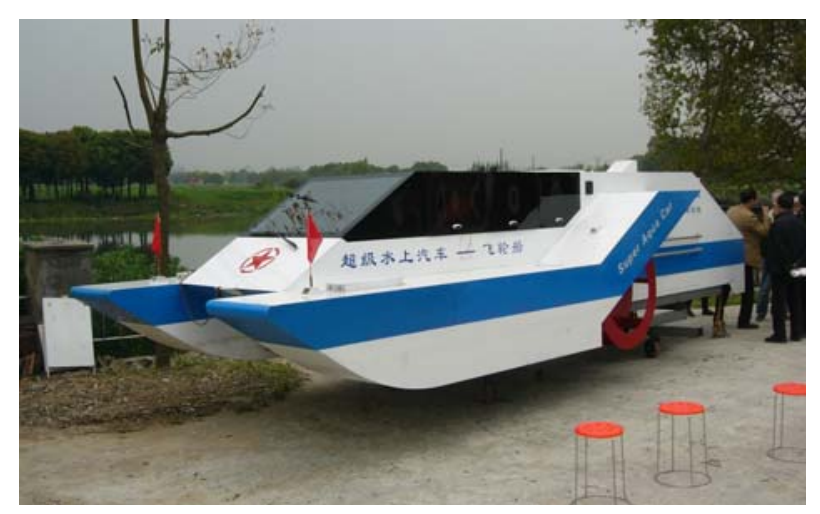

Fig. 5 General view of 6th test craft.

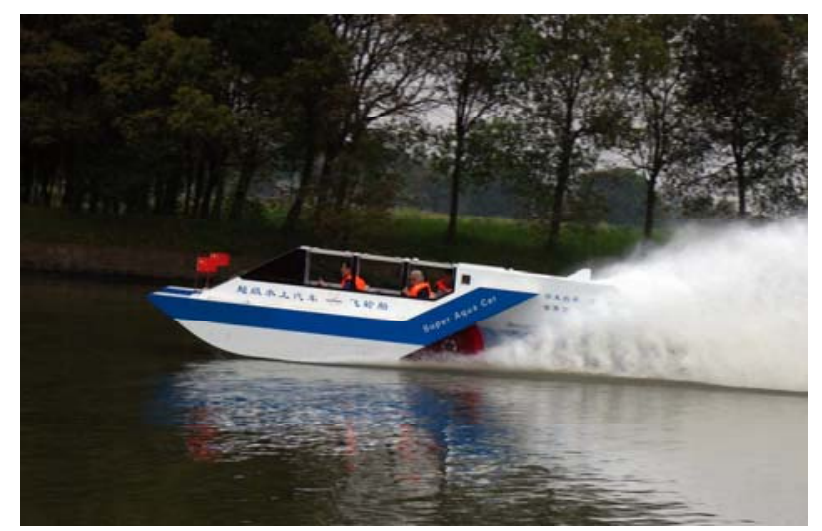

Fig. 6 BLFW craft running at high speed.

\section{Basic Working Mechanism and Main Design Features of the BLFW Craft}

The working mechanism and design features of the BLFW can be outlined as follows:

\subsection{Propulsion System}

A pair of flying wheels are arranged at both sides of the craft, with high revolution, producing both a great lift supporting most part of the craft weight, and thrust as propulsion equipment instead of ordinary propeller (water and air) or water (air) jet propulsion system, so as to obtain both high propulsion and transportation efficiencies at high speed without cavitations obstacle, other disadvantages for the ordinary propellers and high field noise made by aero-dynamics of the air propellers using on the wing in ground effect craft flying in air. The concrete profile of the paddle is shown in Fig. 7.

The structure of the flying wheel is shown in Fig. 8, and according to the high revolution of the flying wheel, the blades of the wheel spanking the water surface and producing a great lift and thrust continuously in terms of spanking frequency (revolution of the wheel) and incident angle $\beta$, so one can see that this wheel is rather different from the paddle of the ancient paddle boat, which not only produce the thrust Fa, but also lift Fu.

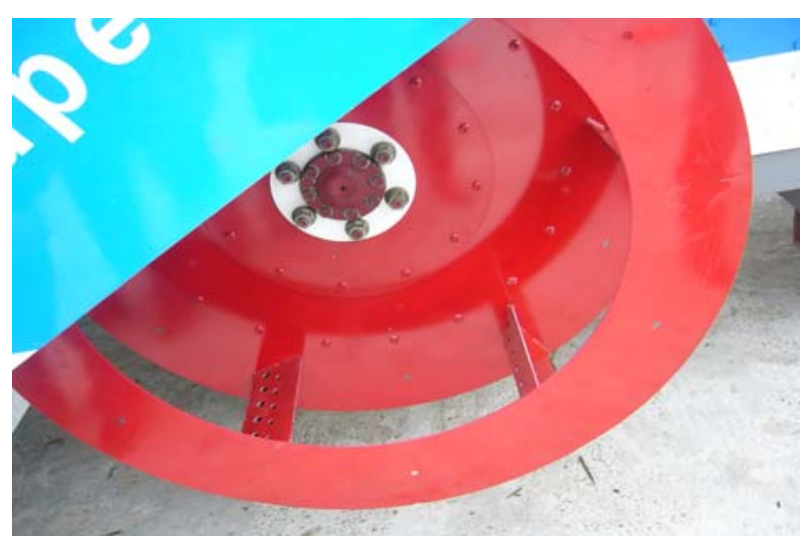

Fig. 7 Profile of the flying wheel.

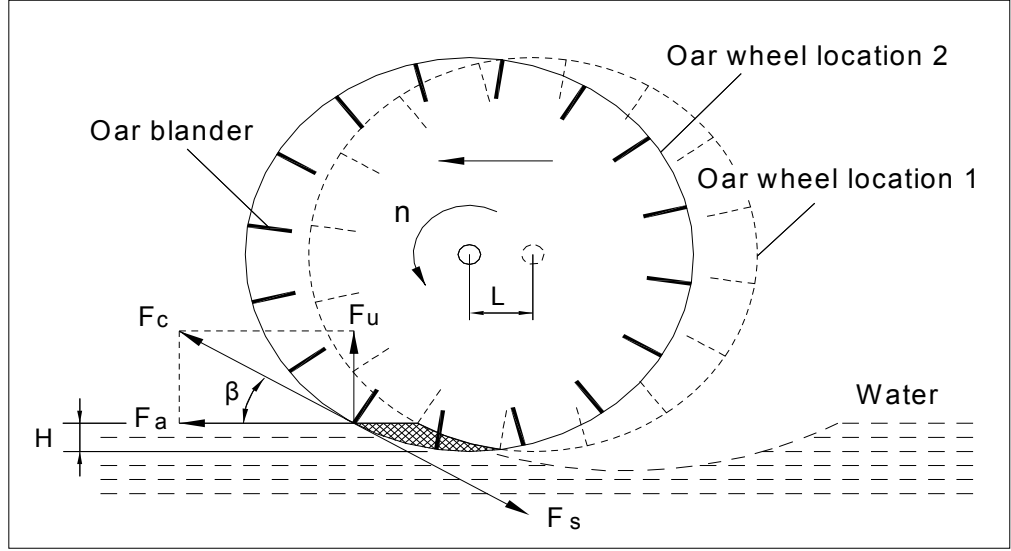

Fig. 8 Structure of the flywheel. 
We also studied the motion of Lizard's palmate feet, and found which is "To and Fro" type of motion with lower frequency, and in order to making flying wheel working continuously, significantly, and practically, we used the "Circular Motion", instead of the "To and Fro" type of motion, as shown in the Fig. 8, and it was apparently that both the lift and thrust and distribution of these forces were according to the revolution of wheel $n$, number of blades $N$, installation and configuration of the blades on the wheel, as well as draft of the wheel $t$, and we could design the flying wheel propulsion system for the real and practical craft.

To sum up, the propulsion system is rather different from the ordinary system, which produces both thrust and lift, and the craft is also rather different from ordinary ships and HPMV, craft weight being supported greatly and partly by propulsion system, other than ordinary four forces, as Buoyancy, Hydrodynamic lift, Aero-dynamic lift, and air cushion lift for the in the HPMV family, and as fifth lifting force.

\subsection{Arrangement of the Flying Wheels}

The flying wheels are arranged at both sides of the craft, and close to the CG (center of gravity) of the craft, so as to lift the craft smoothly at various speed of the craft, from take-off to high speed at Planing mode. At such arrangement, good motion stability, both transverse and longitudinal stability at various motion speed has been obtained in past tested conditions, and we never got any instable motion of the craft at any speed, as well as overturning, which used to be occurred on the fast craft, as racing boat.

\subsection{Arrangement of Planing Surface}

Triple points of Planing surfaces are arranged on the craft for obtaining a high efficiency of hydrodynamic property of the craft at super high speed, with craft weight Froude Number high up to 7-8, far higher than ordinary HPMV (high performance marine vessels), as ACV/SES/HYC/CAT, etc., and even close to the WIG (Wing in Ground Effect Craft). According to the nice general arrangement of the craft, particularly the arrangement of the propulsion system and planing surface, as shown in Figs. 3-5 a good motion stability of the craft in various speed is obtained. The skegs are also arranged at both sides of the rear planing surface for enhancing the hydrodynamic property of the rear planing surface.

\section{Test Results}

At first, tests of some small radio controlled models, length of $0.6 \mathrm{~m}$, weighing $1.6 \mathrm{~kg}$ had been carried out for evidencing the satisfied motion mode, from hull borne, static lift, to take-off, and Planing mode.

Following figures shows the motion of the model, with flying mode being excellent with short TO (take off) distance of only one craft length $L$, and TO time about $2 \mathrm{~s}$, speed $16 \mathrm{~m} / \mathrm{s}$, with super dynamic shallow draft of $0.01 \mathrm{~m}$.

We have constructed seven real manned crafts, and the tests of one of real crafts, i.e. 6th craft was also carried on the Dian Sam Lake, close to Shanghai City, as shown in Figs. 4-6, and the leading specification, test condition, as well as test results are as follows:

\subsection{Leading Specifications}

Weight (full loaded, with four persons) 2,100 kg;

Hull overall length $8.20 \mathrm{~m}$;

Length of main hull $7.50 \mathrm{~m}$;

Width of hull, overall $2.70 \mathrm{~m}$;

Height of hull $1.50 \mathrm{~m}$;

Diameter of flying wheel, D $1.10 \mathrm{~m}$;

Static draft $0.30 \mathrm{~m}$;

Max static draft(from lower edge flying wheel: 0.45 $\mathrm{m}$;

Main engine output 300 hp.

\subsection{Operation Condition}

Weather: most cloud, wind 1-3 scale, with calm water, passenger 2-3,driver 1, craft weight 1.95-2.1 t. 


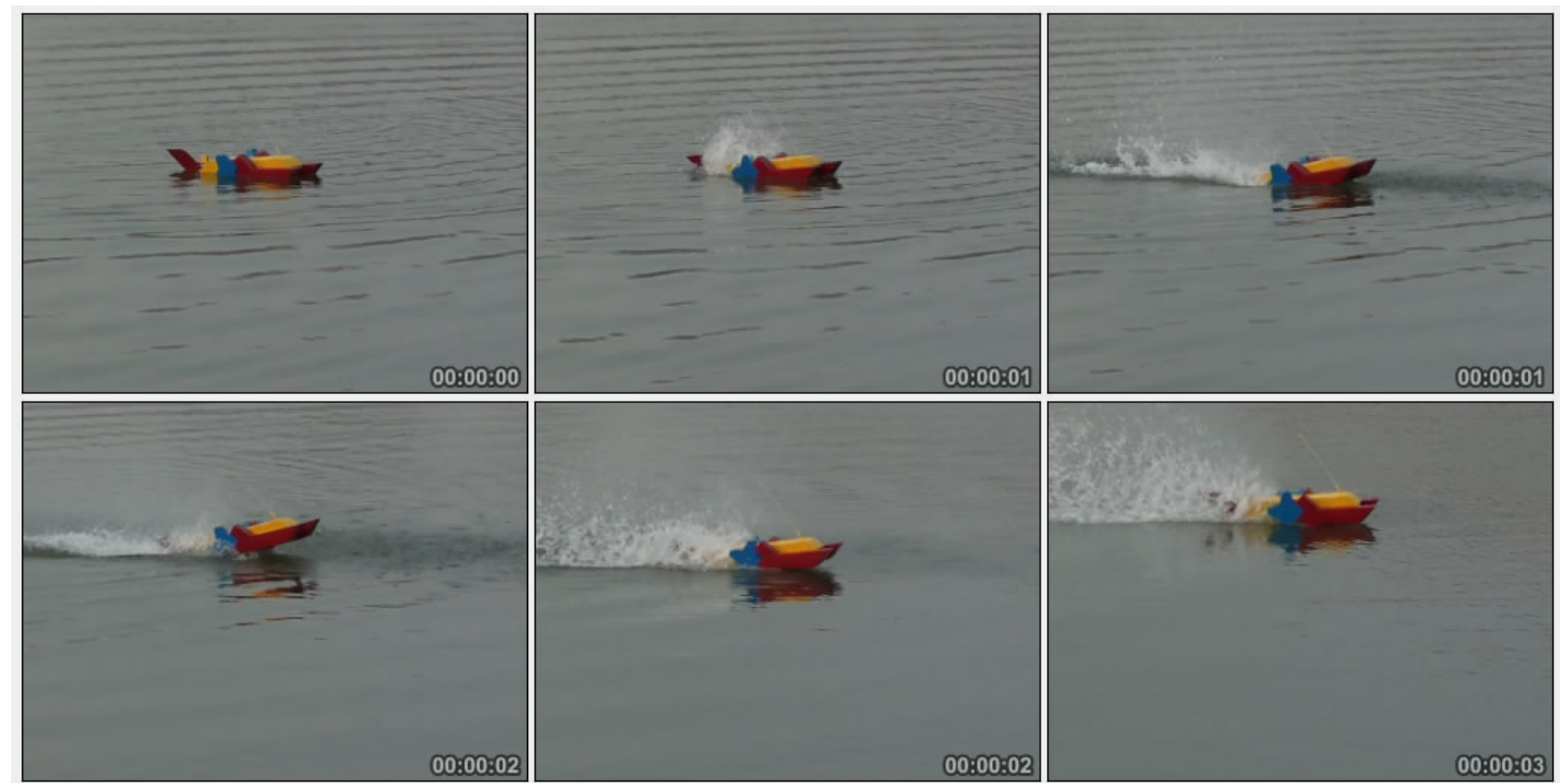

Fig. 9 Motion modes of the radio controlled BLFW model.

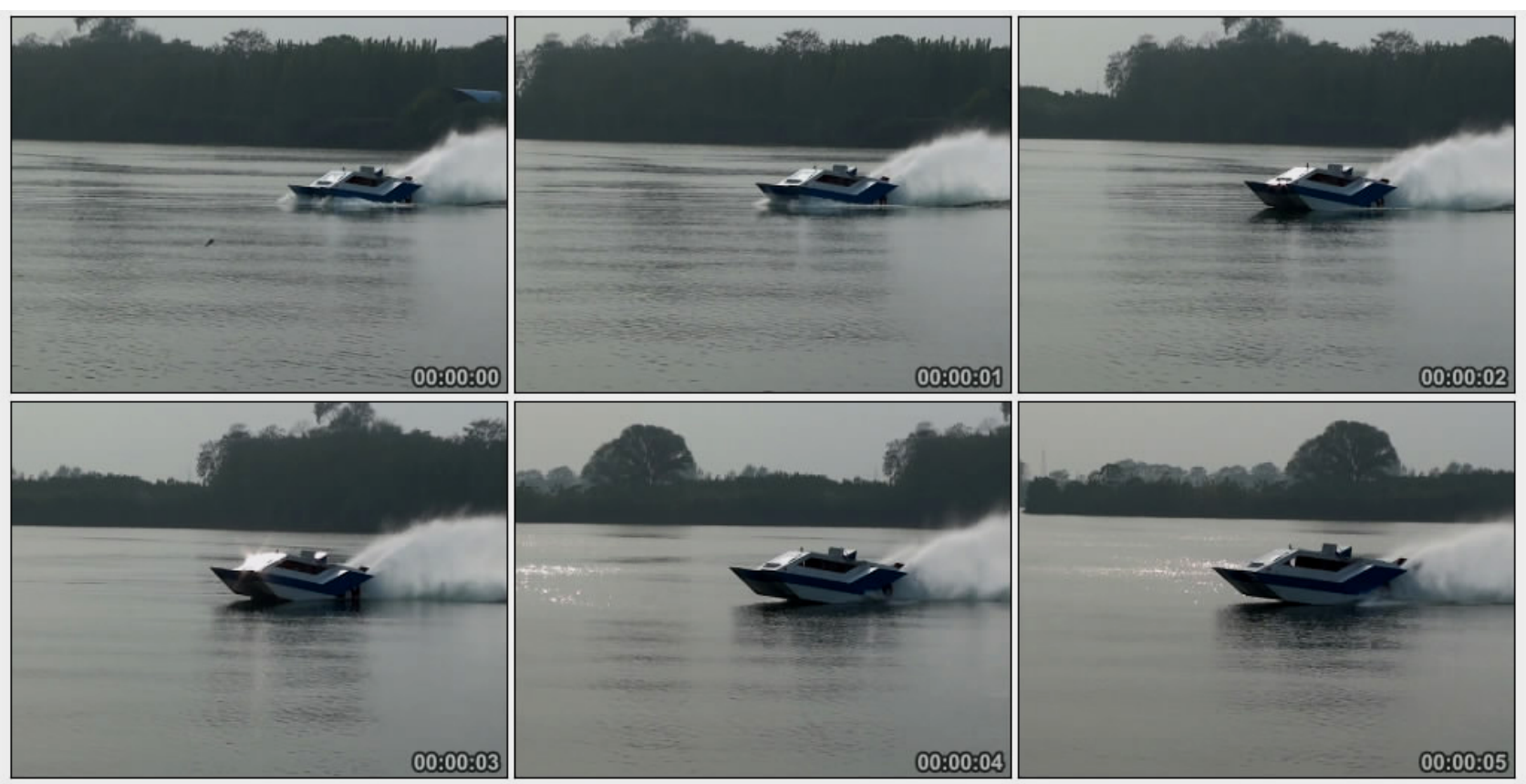

Fig. 10 Running attitude of 6th manned BLFW craft.

\subsection{Test Results}

Speed: $95-100$ km/h (51.3-54 kn);

Main engine output: 300 ps;

Engine revolution: 5,000 rpm;

Min take off time: about $3 \mathrm{~s}$, which in terms of engine output;
Min take off distance: about $10 \mathrm{~m}$ (about $1 \mathrm{~L}$ ).

Engine revolution versus craft speed is as follows:

Engine revolution (rpm)/Craft speed km/h;

3000/TO with speed of about $20 \mathrm{~km} / \mathrm{h}$;

4000/about $60 \mathrm{~km} / \mathrm{h}$;

5000/95-100 km/h.

Following figures show the running attitude of the 
craft during TO and Planing mode at high speed.

\section{Operational Characteristics and Advantages of the BLFW Craft}

(1) High speed with nice speed performance. Since we take special propulsion system, flying wheel, providing not only thrust but also lift, with high propulsion efficiency, and extra lift, other than ordinary supporting force, (as buoyancy for conventional ships, aerodynamic force for Wing in Ground Effect Craft, WIG, hydrodynamic force for Planing hull PH, and hydrofoils, HYC, air cushion lift for air cushion crafts, ACV/SES, etc.), so it is rather different and innovational propulsion system, operating at super high speed at weight Froude number higher up to 7-8, rather different from ACV/SES/HYC, etc., but close to WIG, however, without air propeller with high external field noise. It also is without cavitations obstacle for water propeller.

(2) Extra short take-off distance and time. Just like VTOL (Vertical TO and Landing) and STOL (short take off and landing) characteristics of aircraft, with only 1/10 more shorter TO distance and TO time, compared with other HPMV as ACV/SES/HYC, and even WIG, etc.; and such characteristics of the BLFW possibly is unique in the HPMV family, around the world, due to drastic flywheel lift acting on the craft directly supporting a great part of craft weight so as to make craft jump up or decreasing drastically draft during TO, and making operation mode of the craft from hull borne transferring directly to the planing operation mode, and almost cancel the intermediate mode (or semi-planing mode). However, since the distribution of lift and thrust is in terms of draft, the thrust will be increased automatically after TO, and lift decreased after TO because of drastically decreased of the draft, and the weight of the craft supported mostly by the aero-hydrodynamic lift of planing surfaces.

(5) No hump drag and hump speed. During the TO due to drastic lift of the propulsion system, and craft being with extra small wave making during the TO due to without hump drag, so as to be less disturbance to other ships in narrow water way and pier; and also being favorable to the main engine of the craft.

(4) Extra shallow draft at all operational mode.

(5) Good both transverse and longitudinal stability at super high absolute and relative speed $(\mathrm{Fr})$ due to nice general arrangement of both propulsion system (close to CG), and triple planing surface at fore and rear, and any instable transverse and longitudinal motion (porpoise motion, overturning backward) has been happened in the past tests, however, which used to be happened on racing boat and fast planing hull.

(6) Simple structure of the propulsion system and hull, as well as limited size of the hull, compared with complicated lift system with skirt and big size of air cushion for ACV/SES, automatic system and foil system for HYC, air wing and huge air propellers for WIG, etc., so as to be cost effective, and lower maintenance cost.

(7) Lower external noise at super high speed due to without air propeller, as WIG.

\section{Applications and Prospect}

According to the advantages mentioned above, it is apparently that the BLFW crafts can be used widely in both civil and paramilitary applications, as anti-smuggling crafts, working boats, passenger boat, recreation boat, coastguard patrol boat, yachts, rescue boat, survey boat, etc., operating at shallow water, rapids, swamp, river, lake, as on the upstream of Yangzi River of China, Amazon River of South America, Florida of US, etc., and also tide area with shallow draft, as well as seaside, coastal line and sea.

At present, the seaworthiness of the BLFW crafts with rather big size has been planning to be investigated for more widely application of the craft, and hopefully it will be more emphasized with bright prospect in the HPMV family, around the world. 


\section{Conclusion}

A novel and innovative special propulsion system, Bionic Lizard Flying Wheel, has been inventing and researching as well as developing by Mr. Liang Hou, the President, Chief designer, Technical Director of the XIYI High Speed Craft Bionic Science and Technology Ltd (XYL), Shanghai, China, after 30 years investigation in China, and which has also successfully being used on the super high speed planing craft with displacement Froude Number, Fr, high up to 7-8, and speed 50-60 $\mathrm{kn}$ on the craft weighing only $2 \mathrm{t}$, with good motion stability, high hydrodynamic property, and propulsion efficiency, STOL characteristics (TO distance only $1 \mathrm{~L}$, TO time around $3 \mathrm{~s}$ ), super shallow draft, simple structure, limited profile dimension, cost effectiveness, less field noise, etc. and believably that it should be first of this kind in the HPMV family and a significant science and technology break through in the shipping as well as unique innovation around the world so far.

In addition, this is a basically revolutionary innovation of the propulsion for all ships and boats, which provides not only thrust but also lift for the craft, so as to obtain a great advantages and characteristics, such as STOL (even without semi-planing operation mode for his $\mathrm{HSPH}$, high speed planing hull), and nice speed performance as well as also sea-keeping quality, etc., so a huge revolutionary change may be happened in ship performance later, fallowing with the progress of the technology, and application of the BLWF, which we even are not being able to expect precisely right now, so we can conclude that the aim of the technology research right now is: for both civil and military, including para-military application, mentioned above. 